\title{
Evolution of T1 Relaxation, ADC, and Fractional Anisotropy during Early Brain Maturation: A Serial Imaging Study on Preterm Infants
}

\author{
(D). Schneider, T. Kober, M. Bickle Graz, (D) R. Meuli, P.S. Hüppi, P. Hagmann, and A.C. Truttmann
}

\begin{abstract}
BACKGROUND AND PURPOSE: The alteration of brain maturation in preterm infants contributes to neurodevelopmental disabilities during childhood. Serial imaging allows understanding of the mechanisms leading to dysmaturation in the preterm brain. The purpose of the present study was to provide reference quantitative MR imaging measures across time in preterm infants, by using ADC, fractional anisotropy, and $\mathrm{Tl}$ maps obtained by using the magnetization-prepared dual rapid acquisition of gradient echo technique.
\end{abstract}

MATERIALS AND METHODS: We included preterm neonates born at $<30$ weeks of gestational age without major brain lesions on early cranial sonography and performed 3 MRIs (3T) from birth to term-equivalent age. Multiple measurements (ADC, fractional anisotropy, and $\mathrm{T} 7$ relaxation) were performed on each examination in 12 defined white and gray matter ROIs.

RESULTS: We acquired 107 MRIs (35 early, 33 intermediary, and 39 at term-equivalent age) in 39 cerebral low-risk preterm infants. Measures of T7 relaxation time showed a gradual and significant decrease with time in a region- and hemispheric-specific manner. ADC values showed a similar decline with time, but with more variability than $\mathrm{T} 1$ relaxation. An increase of fractional anisotropy values was observed in WM regions and inversely a decrease in the cortex.

CONCLUSIONS: The gradual change with time reflects the progressive maturation of the cerebral microstructure in white and gray matter. Our study provides reference trajectories from 25 to 40 weeks of gestation of T1 relaxation, ADC, and fractional anisotropy values in low-risk preterm infants. We speculate that deviation thereof might reflect disturbed cerebral maturation; the correlation of this disturbed maturation with neurodevelopmental outcome remains to be addressed.

ABBREVIATIONS: FA = fractional anisotropy; GA = gestational age; MP2RAGE = magnetization-prepared dual rapid acquisition of gradient echo; $\mathrm{PLIC}=$ posterior limb of the internal capsule; $R_{\text {adj }}{ }^{2}=$ correlation coefficient adjusted for the degree of freedom; TEA = term-equivalent age; GRAPPA = generalized autocalibrating partially parallel acquisition

O ffering a prognosis for the neurodevelopment of very preterm infants remains a challenge, as has recently been shown. ${ }^{1}$ Yet, prematurity still carries a high burden of impairment

Received April 7, 2015; accepted after revision June 11

From the Clinic of Neonatology and Follow-up (J.S., M.B.G., A.C.T.), Department of Pediatrics, and Department of Radiology (T.K., R.M., P.H.), University Hospital Center and University of Lausanne, Lausanne, Switzerland; Advanced Clinical Imaging Technology (T.K.), Siemens Healthcare IM BM PI, Lausanne, Switzerland; LTS5 (T.K.), École Polytechnique Fédérale de Lausanne, Lausanne, Switzerland; and Division of Development and Growth (P.S.H.), Department of Pediatrics, University Hospital of Geneva, Geneva, Switzerland.

Patric Hagmann and Anita C. Truttmann contributed equally to the study as last coauthors.

This work was funded by a Special Program University Medicine from the Swiss National Science Foundation (number 33CM30-124101). Patric Hagmann is financially supported by the Leenaards Foundation. This work was supported by the Centre d'Imagerie BioMédicale of the University of Lausanne, the Swiss Federal Institute of Technology Lausanne, the University of Geneva, the Centre Hospitalier Universitaire Vaudois, the Hôpitaux Universitaires de Genève, and the Leenaards and the Jeantet Foundations. in survivors, affecting motor, cognitive, and socioemotional development. ${ }^{2,3}$ While the motor deficits are frequently linked to moderate or severe WM lesions such as cystic periventricular leukomalacia or large intraparenchymal hemorrhage, the cognitive abnormalities are probably more related to the mixed picture of brain injury and alteration of cerebral development, ${ }^{4}$ coined by Volpe as diffuse encephalopathy of prematurity. ${ }^{5}$ A large body of work in the past decades has been devoted to new techniques of

Paper previously presented at: Annual Meeting of the European Society of Paediatric Research, October 11-14, 2013; Porto, Portugal; and Annual Meeting of the Pediatric Academic Societies, April 28 to May 1, 2012; Boston, Massachusetts.

Please address correspondence to Anita C. Truttmann, MD, Service de Néonatologie, Département médico-chirurgical de Pédiatrie, Maternité-CHUV, Ave PierreDecker 2, 1011 Lausanne, Switzerland; e-mail: Anita.Truttmann@chuv.ch

- Indicates open access to non-subscribers at www.ajnr.org

三 Indicates article with supplemental on-line tables.

Indicates article with supplemental on-line photo.

http://dx.doi.org/10.3174/ajnr.A4510 
MR imaging, specifically addressing the question of the maturation of the preterm brain.

Longitudinal imaging of the growing brain between 25 and 40 weeks of gestation allows assessing neuronal differentiation, gyral maturation, connecting fiber development, and early myelination. ${ }^{6}$ To analyze these features of normal/abnormal maturation, efficient tools and reference values are still lacking. Several authors have described serial quantitative measures by using apparent diffusion coefficients and fractional anisotropy (FA) in various cohorts. $^{7-11}$ These sequences probe tissue microstructure and are used as markers of maturation, especially for axonal and dendritic organization and myelination. Recently, magnetizationprepared dual rapid acquisition of gradient echo (MP2RAGE) emerged as a new technique, which, by obtaining a purely T1weighted image, allows the extraction of whole-brain T1 tissue relaxation time maps to provide quantitative tissue characterization. ${ }^{12}$ The descriptive properties of $\mathrm{T} 1$ relaxometry are of particular interest in the preterm population because they give structural information about tissue, such as water content and lipid and macromolecule composition, and draw a picture of the chronologic maturation of myelin. Moreover, there is a lack of quantitative T1 values for the assessment of brain development. ${ }^{11,13-15}$

In this serial imaging study in very preterm infants with cerebral low risk, we aimed to provide, for the first time, reference values for $\mathrm{T} 1$ relaxation time, and we hypothesized that their evolution is comparable with that of ADC and FA values, conferring greater and more precise information about tissue structure.

\section{MATERIALS AND METHODS \\ Patients}

Neonates born before 30 weeks of gestation between February 2011 and May 2013 in our level III neonatology unit were considered for inclusion during the first days of life. Noninclusion criteria were the following: severe cardiorespiratory instability, intraventricular hemorrhage grade III and/or parenchymal hemorrhagic infarction on early sonography, severe congenital malformations, and genetic abnormalities. Patients who subsequently developed severe lesions on MR imaging, who died during the study, or who had abnormal neurologic assessment at term equivalent age (TEA) according to the Hammersmith Neonatal Neurologic Examination ${ }^{16}$ were excluded from the final analysis. We thus defined the remaining patients as "cerebral low-risk." Neonatal variables were registered prospectively from the medical records.

Ethics approval was provided by the local committee, and written informed consent was obtained. Specific risks arising from imaging children younger than 2 years of age were assessed by the medical team and the institutional review board before the MR imaging examination.

\section{MR Imaging}

We planned 3 sequential MRIs: The first was during the first 2-3 weeks of life, the third at TEA, and the second in-between (from 10 to 20 days of life for the first part of the cohort and at 34-35 weeks of gestational age for the second part). All MRIs were performed on a 3T Magnetom Trio system (Siemens, Erlangen, Germany). A neonatal MR imaging-compatible incubator (Nomag; LMT Medical Systems, Luebeck, Germany) equipped with a ded- icated 8-channel neonatal head coil was used. Monitoring was provided during scanning (temperature, heart rate, oxygen saturation), and respiratory support was applied when necessary. Patients received no sedation and wore protective earmuffs (MiniMuffs; Natus Medical, San Carlos, California). A neonatologist and a neonatal nurse were present throughout the examination. The cerebral MR imaging protocol included the following: 1) inversion recovery T1-weighted TSE axial (in-plane resolution, $0.6 \mathrm{~mm}$; section thickness, $3 \mathrm{~mm}$ with $10 \%$ gap; 35 sections; TR, $8000 \mathrm{~ms}$; TE, $17 \mathrm{~ms}$; FOV, $160 \mathrm{~mm}$; acceleration factor generalized autocalibrating partially parallel acquisition (GRAPPA) $=2$; measurement time, 3 minutes 14 seconds); 2) T2-weighted TSE axial (in-plane resolution, $0.2 \mathrm{~mm}$; section thickness, $2.5 \mathrm{~mm}$ with a 10\% gap; 35 sections; TR, 4520 ms; TE, 143 ms; FOV, 160 mm; acceleration factor GRAPPA $=2$; measurement time, 4 minutes 15 seconds); 3) T2-weighted TSE coronal (in-plane resolution, 0.4 $\mathrm{mm}$; section thickness, $1.2 \mathrm{~mm}$ with a $10 \%$ gap; 100 sections; TR, $5410 \mathrm{~ms}$; TE, $159 \mathrm{~ms}$; FOV, $200 \mathrm{~mm}$; acceleration factor GRAPPA $=2$; measurement time, 4 minutes 59 seconds); 4) 3D MP2RAGE (in-plane resolution, $0.7 \mathrm{~mm}$; section thickness, $1.2 \mathrm{~mm}$; TR, 4000 ms; TE, 3.17 ms; FOV, 190 mm; TI 1, 900 ms; TI 2, 2200 ms; acceleration factor GRAPPA $=2$; measurement time, 4 minutes 58 seconds); 5) DTI (in-plane resolution, $2 \mathrm{~mm}$; section thickness, 2 mm with no gap; 43 sections; TR, 5200 ms; TE, 84 ms; FOV, 192 mm; b-value $1,0 \mathrm{~s} / \mathrm{mm}^{2}$; b-value 2, $1000 \mathrm{~s} / \mathrm{mm}^{2}$; diffusion encoding directions, 82 and 5 B0 images; acceleration factor GRAPPA = 3; measurement time, 7 minutes 29 seconds). The standard ADC and FA maps generated by the scanner software were used in this study. No additional motion and eddy current corrections were performed. The vendor computes ADC and FA maps according to Basser et $\mathrm{al}^{17}$ by using a least square estimation of the tensor.

Using T2, inversion recovery T1, and MP2RAGE, we calculated scores for severity at TEA according to Kidokoro et al, ${ }^{18}$ including 6 items in the WM and 7 items in the GM and cerebellum. A global score (WM + GM and cerebellum score) was calculated and classified as normal ( $0-3)$, mild $(4-7)$, moderate (8$11)$, and severe $(\geq 12)$. Two neonatologists experienced in reading MR imaging calculated the score. Intraventricular hemorrhages were graded according to Papile, ${ }^{19}$ and WM and cerebellar lesions were also described.

Twelve ROIs were identified with anatomic landmarks on 5 different sections for the WM (frontal, central, parietal, posterior limb of internal capsule [PLIC]; corpus callosum genu and splenium; and optic radiations) and the GM (frontal, perirolandic, and parietal cortices; thalamus; and lentiform nucleus). Freehand ROIs were drawn to maximize the size and avoid the risk of GM/WM contamination, as shown in On-line Fig 1. Each ROI was placed on the DTI sequence to measure ADC and FA and on the T1 map obtained from the MP2RAGE sequence to calculate the effective $\mathrm{T} 1$ relaxation time. ${ }^{12}$

\section{Neurodevelopmental Outcome}

The patients were offered neurodevelopmental follow-up at 6 and 18 months of corrected age. A developmental pediatrician blinded to the neuroimaging findings performed a developmental assessment by using the Bayley Scales of Infant Development II, which entails a mental developmental index and a psychomotor devel- 
Clinical variables describing the total population, the low-risk cohort, and the excluded patients ${ }^{a}$

\begin{tabular}{|c|c|c|c|c|}
\hline & Total Cohort & Low-Risk Cohort & Excluded & $P$ Value ${ }^{b}$ \\
\hline No. of patients (\%) & 51 & $39(76.5)$ & $12(23.5)$ & \\
\hline GA (weeks, days) (median) (range) & $274 / 7(250 / 7-314 / 7)$ & $274 / 7(25$ 5/7-30) & $281 / 7(250 / 7-314 / 7)$ & NS \\
\hline Female (No.) (\%) & $29(56.9)$ & $19(48.7)$ & $10(83)$ & $<.05$ \\
\hline Weight (g) (median) (range) & $889(517-1590)$ & $900(560-1485)$ & $727.5(517-1590)$ & NS \\
\hline Small for GA (weight < 10th percentile) (No.) (\%) & $12(23.5)$ & $8(20.5)$ & $4(33.3)$ & NS \\
\hline Multiple births (No.) (\%) & $12(23.5)$ & $6(15.4)$ & $6(50)^{\prime}$ & $<.05$ \\
\hline Chorioamnionitis (No.) (\%) & $21(41.2)$ & $16(41.0)$ & $5(41.7)$ & NS \\
\hline Antenatal steroids (No.) (\%) & $45(88.2)$ & $34(87.2)$ & $11(91.7)$ & NS \\
\hline All BPD/severe BPD (No.) (\%) & $26(51.0) / 9(17.6)$ & $17(43.6) / 5(12.8)$ & $9(75.0) / 4(33.3)$ & NS \\
\hline Postnatal steroids (No.) (\%) & $7(13.7)$ & $2(5.1)$ & $5(41.7)$ & $<.05$ \\
\hline Treated patent ductus arteriosus (No.) (\%) & $25(49.0)$ & $17(43.6)$ & $8(66.7)$ & NS \\
\hline Early-onset sepsis (No.) (\%) & $13(25.5)$ & $11(28.2)$ & $2(16.7)$ & NS \\
\hline Late-onset sepsis (No.) (\%) & $17(33.3)$ & $13(33.3)$ & $4(33.3)$ & NS \\
\hline Necrotizing enterocolitis (No.) (\%) & $2(3.9)$ & $0(0)$ & $2(16.7)$ & NS \\
\hline Treated retinopathy of prematurity (No.) (\%) & $3(5.9)$ & $1(2.6)$ & $2(16.7)$ & NS \\
\hline Death (No.) (\%) & $2(3.9)$ & $0(0)$ & $2(16.7)$ & NS \\
\hline 6-Mo MDI (median) (range) & $98(74-118)$ & $98(86-118)$ & 93 (74-102) & $<.05$ \\
\hline 6-Mo PDI (median) (range) & 88 (49-111) & $88(62-111)$ & $78.5(49-88)$ & $<.05$ \\
\hline 18-Mo MDI (median) (range) & $93(65-127)$ & $93(65-127)$ & 87 (79-101) & NS \\
\hline 18-Mo PDI (median) (range) & $83(49-103)$ & $84(55-103)$ & $71(49-95)$ & $<.05$ \\
\hline
\end{tabular}

Note:-MDI indicates mental developmental index; PDI, psychomotor developmental index; BPD, bronchopulmonary dysplasia; NS, nonsignificant.

a Bronchopulmonary dysplasia: $\mathrm{O}_{2}$ supplementation for 28 days. Severe BPD: respiratory support at 36 weeks of GA. Necrotizing enterocolitis: Bell stage $>2$.

b Between low-risk cohort and excluded patients.

opmental index. The test mean is $100 \pm 15$; a score $<2$ SDs means a severe delay.

\section{Statistical Analyses}

Statistical analyses were performed by using Matlab R2014b (MathWorks, Natick, Massachusetts) and STATA 13.0 (StataCorp, College Station, Texas). The different associations were analyzed with linear and quadratic regression. The correlation coefficient adjusted for the $d f\left(R_{\mathrm{adj}}{ }^{2}\right)$ was used to identify the model with the best explanatory power. The Pearson linear correlation (R) was used to compare T1 relaxation time and ADC or FA values. The dispersion of ADC and T1 values was compared with a 1-sided $t$ test applied on the normalized root mean square error of each marker. Demographic and neonatal variables were compared with the Student $t$ test (continuous variables) and with the Fisher exact test (categoric variables). Statistical significance was defined as $P<.05$.

\section{RESULTS}

\section{Description of the Population}

Among 126 eligible patients, 51 preterm neonates were recruited. Reasons for not being included were parental refusal $(n=26)$, early death $(n=9)$, cardiorespiratory instability $(n=13)$, early transfer to peripheral hospital $(n=11)$, or absent recruiting person $(n=16)$. Twelve patients were excluded from the final analysis because of severe lesions on brain MR imaging (MR imaging scores $\geq 8$ or parenchymal hemorrhagic infarction), death, withdrawal of consent, or abnormal neurologic examination findings at TEA. We thus show the characteristics of the population based on 39 cerebral low-risk preterm neonates (Table).

\section{Conventional MR Imaging and Scoring System}

One hundred seven MR imaging examinations were performed; 35 early, 33 intermediary, and 39 at TEA. Thirty patients underwent 3 serial MRIs, 8 patients had 2, and 1 patient had only 1 . The assessment of the image quality allowed considering $86 \%$ of the scans as good or with minimal motion artifacts.

Several mild cerebral lesions were diagnosed on the conventional sequences, including intraventricular hemorrhages grade I $(n=5)$ and grade II $(n=2)$, punctuate WM lesions $(n=3)$, and punctuate cerebellar hemorrhages $(n=4)$. Two patients had 2 types of lesions (intraventricular hemorrhage grade I and punctuate WM lesions).

The scoring system could be applied on 37 MRIs at TEA: The global score was within the normal range for 16 and mildly abnormal for 21 patients, and no patient had a moderate or severe score. The MR images and scoring system, including brain metrics, are detailed in On-line Table 1.

\section{Quantitative Measures}

$\mathrm{T} 1$ Relaxation. In Fig 1A, T1 relaxation values (milliseconds) measured in the 12 ROIs of the right and left hemispheres on the serial images of the 39 patients are presented. Maturation in the different cerebral regions was reflected by a gradual decrease of T1 with time. The PLIC matured the fastest $\left(R_{\mathrm{adj}}{ }^{2}=0.8242, P=\right.$ $\left.8.09 \times 10^{-81}\right)$. The values in the $\mathrm{WM}$ of the corona radiata showed a fast and continuous decrease until TEA $\left(R_{\mathrm{adj}}{ }^{2}=0.663, P=1.61 \times\right.$ $\left.10^{-51}\right)$. The parietal $\left(R_{\mathrm{adj}}^{2}=0.2833, P=2.00 \times 10^{-17}\right)$ and frontal $\mathrm{WM}\left(R_{\mathrm{adj}}^{2}=0.0803, P=5.65 \times 10^{-6}\right)$ matured along a shouldered curve, which peaks around 30 weeks of gestational age (GA). The deep GM matured simultaneous to WM, especially the thalamus $\left(R_{\mathrm{adj}}^{2}=0.6814, P=5.66 \times 10^{-49}\right)$ and the lentiform nucleus $\left(R_{\mathrm{adj}}{ }^{2}\right.$ $\left.=0.3747, P=1.06 \times 10^{-24}\right)$. The cortex showed little change with time. The maturation in the different areas of the cortex at TEA was gradual: first in the perirolandic, then in the parietal, and finally in the frontal cortex (see On-line Table 2 for T1 values).

$\mathrm{ADC}$ values are represented in Fig $1 B$, and strengths of the correlations were less strong in almost all the regions (PLIC: $R_{\mathrm{adj}}{ }^{2}=0.4816, P=8.31 \times 10^{-32}$; central WM: $R_{\mathrm{adj}}{ }^{2}=0.566, P=$ 

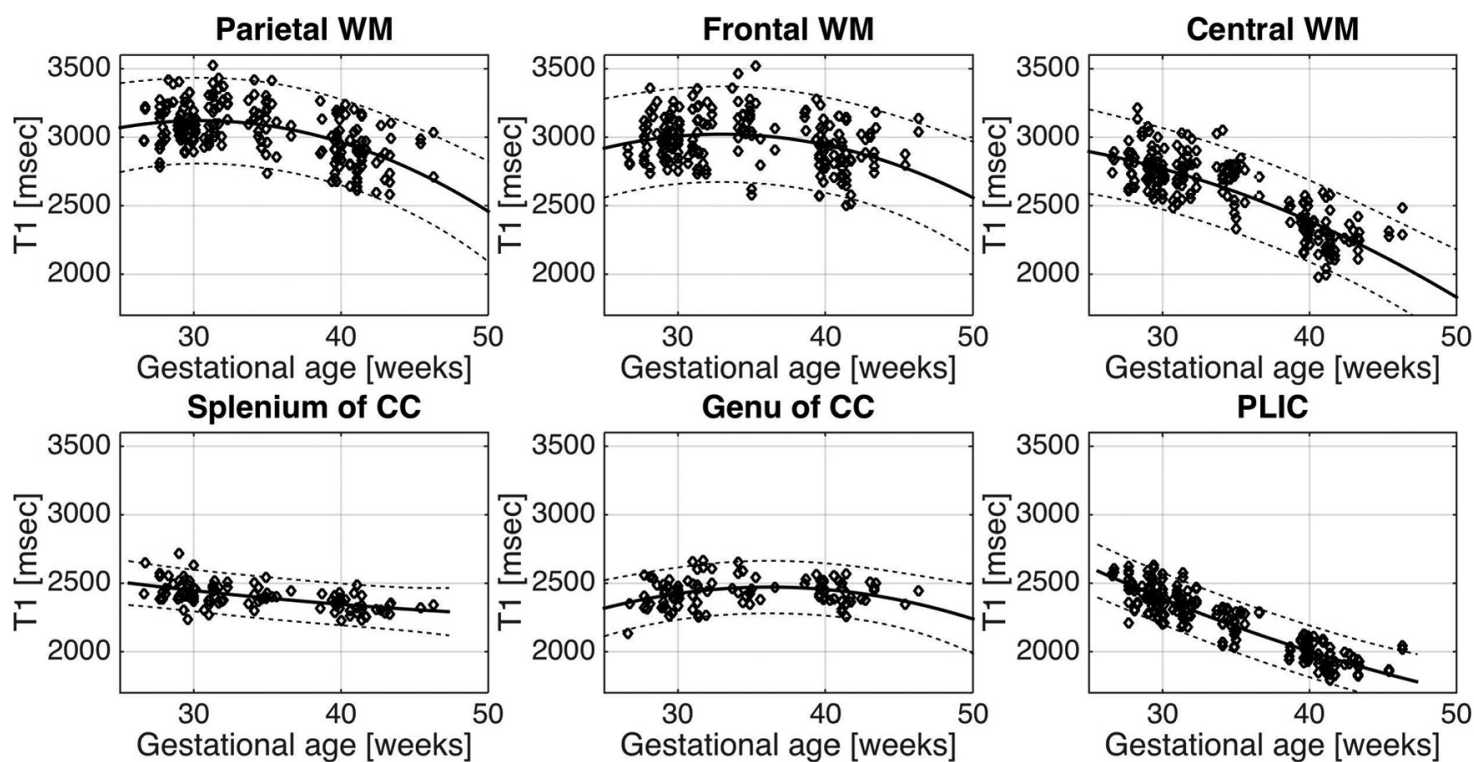

Optic radiation

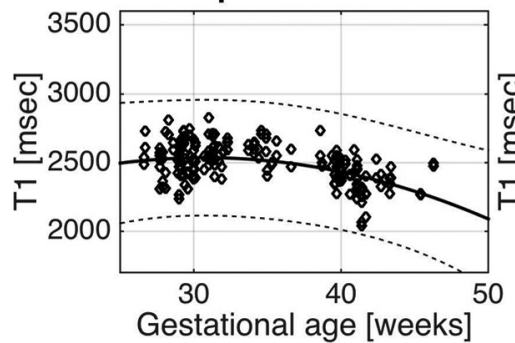

Parietal cortex
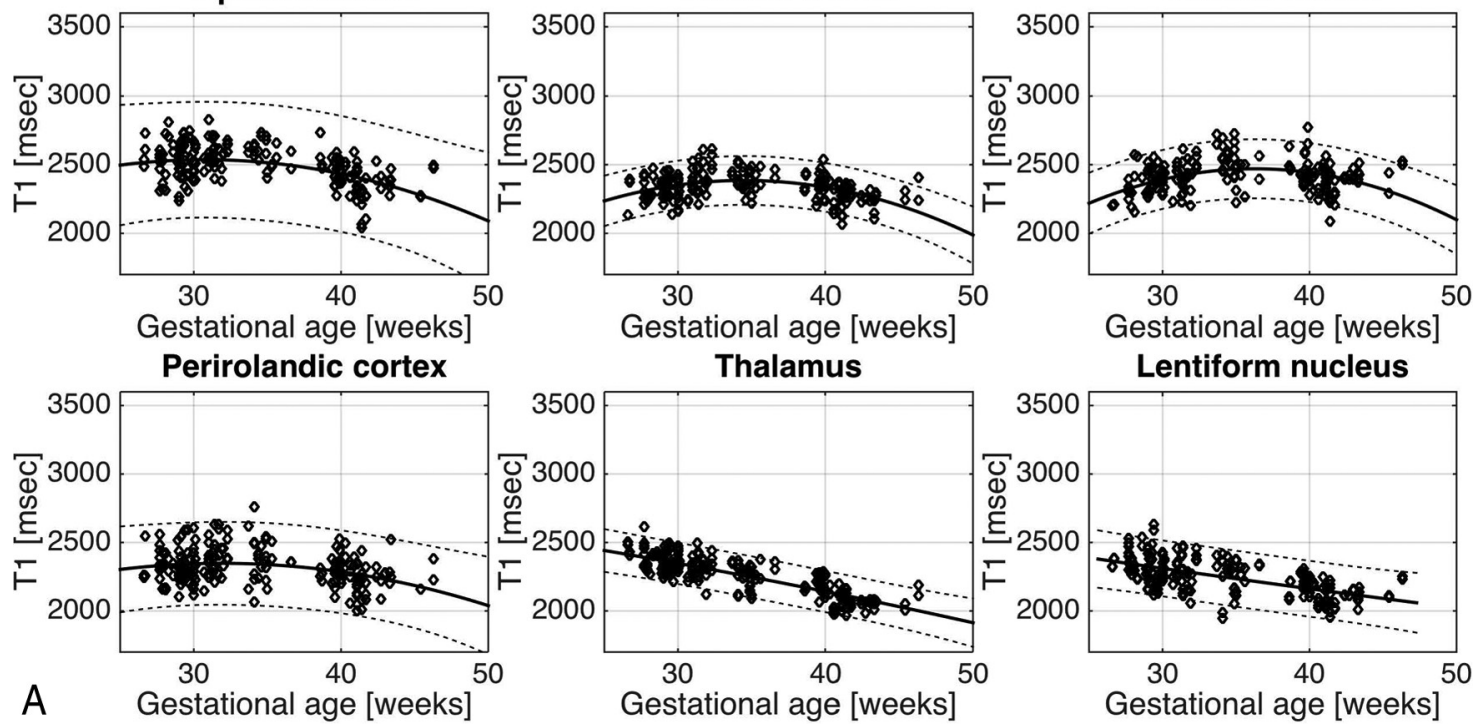

FIG 1. MR imaging values measured in the right and left hemispheres between 25 and 40 weeks of gestational age in 12 ROls for the low-risk cohort of 39 patients. Dotted lines indicate $95 \%$ confidence interval. CC indicates corpus callosum. T1 values $(A)$, ADC values $(B)$, FA values (C).

$2.54 \times 10^{-40}$; thalamus: $\left.R_{\mathrm{adj}}^{2}=0.4855, P=9.42 \times 10^{-32}\right)$, except for parietal WM $\left(R_{\mathrm{adj}}^{2}=0.3048, P=1.20 \times 10^{-18}\right)$, frontal WM $\left(R_{\mathrm{adj}}^{2}=0.312, P=4.05 \times 10^{-19}\right)$, and the lentiform nucleus $\left(R_{\mathrm{adj}}^{2}=0.6718, P=3.20 \times 10^{-52}\right)$.

The evolution of FA with time is shown in Fig $1 C$. The maturation was most visible in the PLIC $\left(R_{\text {adj }}^{2}=0.5386, P=5.19 \times\right.$ $\left.10^{-37}\right)$, the optic radiation $\left(R_{\mathrm{adj}}^{2}=0.3465, P=3.05 \times 10^{-21}\right)$, and the corpus callosum (splenium: $R_{\mathrm{adj}}{ }^{2}=0.2159, P=5.24 \times$ $10^{-7}$; genu: $R_{\mathrm{adj}}^{2}=0.1126, P=9.27 \times 10^{-5}$ ), with a gradual increase in these regions. At the same time, FA decreased in the cortical GM (parietal: $R_{\mathrm{adj}}{ }^{2}=0.4535, P=1.70 \times 10^{-31}$; frontal: $R_{\mathrm{adj}}^{2}=0.199, P=3.67 \times 10^{-12}$; perirolandic: $R_{\mathrm{adj}}^{2}=0.4889$, $\left.P=7.50 \times 10^{-32}\right)$.

For each ROI, we produced reference values stratified by gestational weeks, expressed as mean \pm SD for T1, ADC, and FA (On-line Table 2).

There was a significant and strong correlation between the T1 relaxation time and ADC values for all the ROIs and all MR im- ages at different gestational ages (Pearson correlation $R^{2}=0.616$, $P<.001)$. Furthermore, T1 values exhibited a significantly lower dispersion than ADC values $\left(P=1.06 \times 10^{-4}\right)$. The correlation between T1 relaxation and FA (Pearson correlation $R^{2}=-0.128$ ) was negative and less significant.

\section{DISCUSSION}

The present study provides quantitative reference values for cerebral development, based on 107 MRIs acquired between 25 and 40 weeks in 39 very preterm infants. We used a newly developed sequence, MP2RAGE, which gives the T1 relaxation time, and compared it with MR imaging markers, ADC and FA. The selected cohort can be considered cerebral-low-risk, according to the exclusion criteria. Our findings were comparable with existing data (On-line Tables 3 and 4) issued from fetuses and preterm infants, detailed below.

Given fetal diffusion values and maturation curves obtained between 22 and 36 weeks, our findings of ADC and FA values were comparable with the ones presented by different groups, ${ }^{20-22}$ 


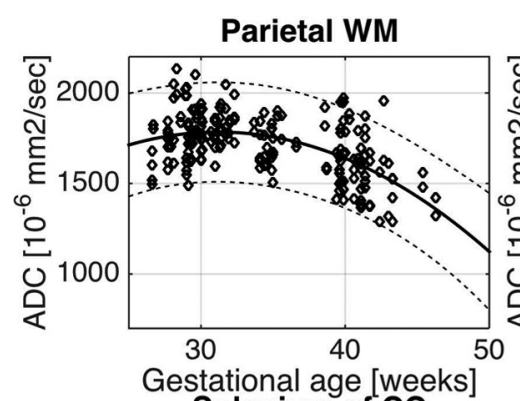

Splenium of CC

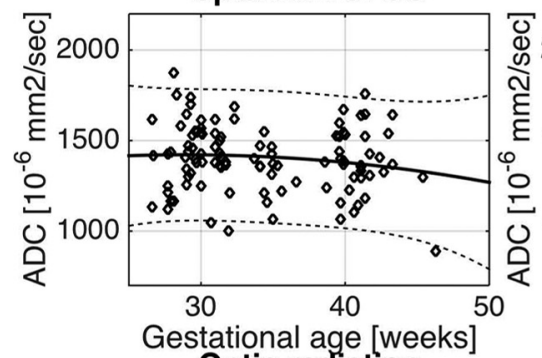

Optic radiation
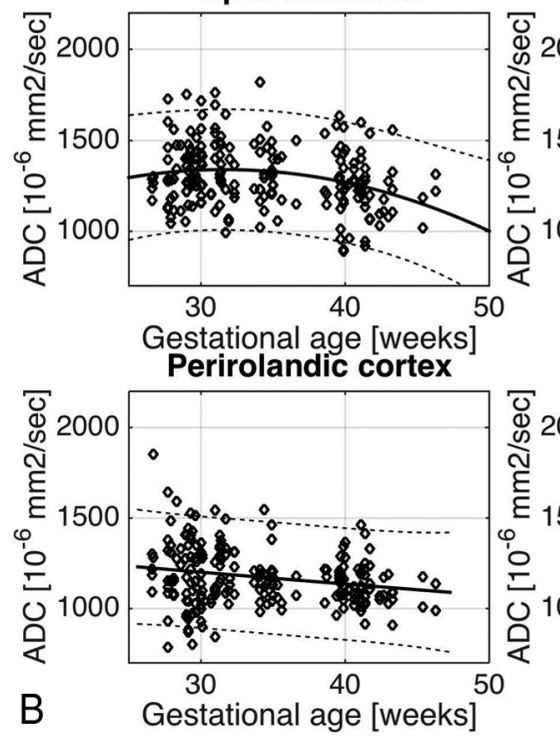

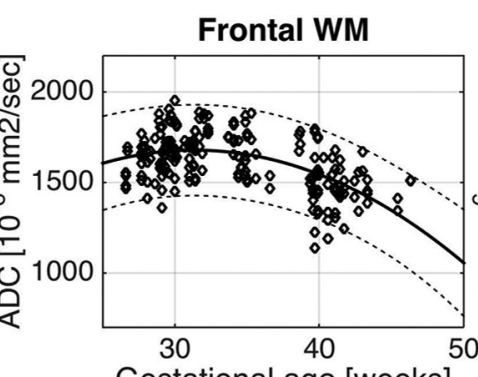

Gestational age [weeks] Genu of CC

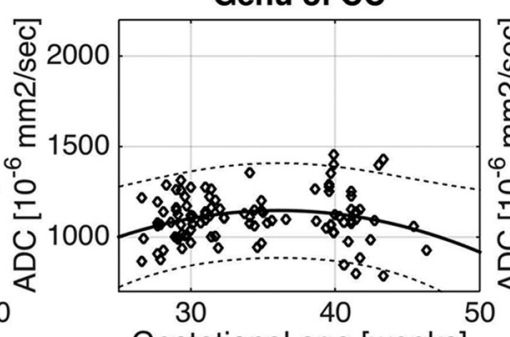

Gestational age [weeks] Parietal cortex

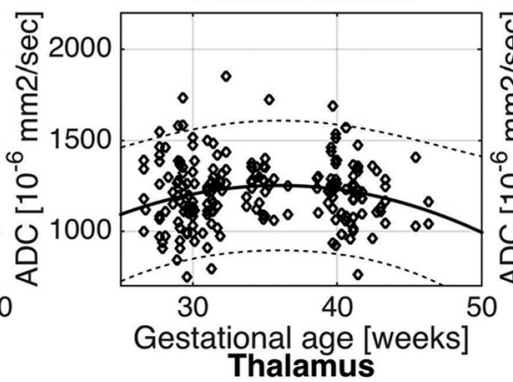

Gestational age [weeks]
Thalamus

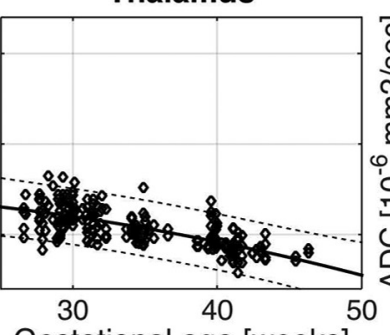

Gestational age [weeks]

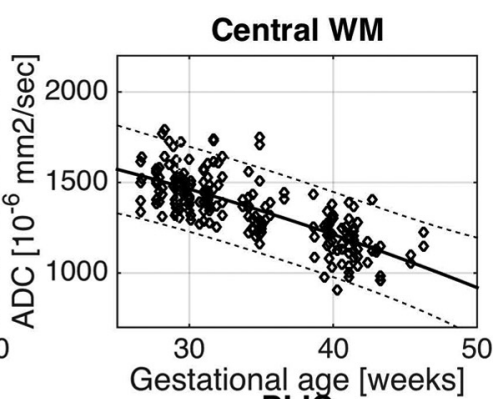

PLIC

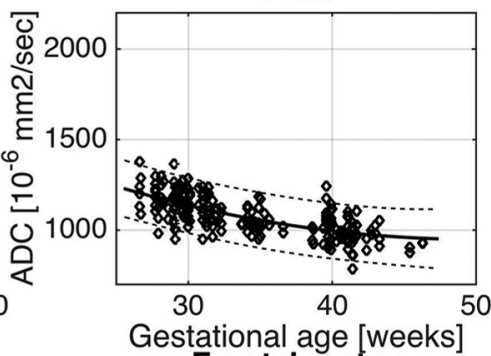

Frontal cortex

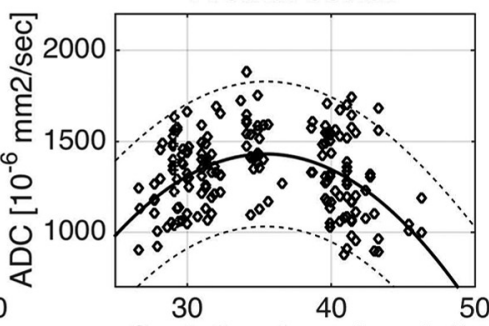

Gestational age [weeks] Lentiform nucleus

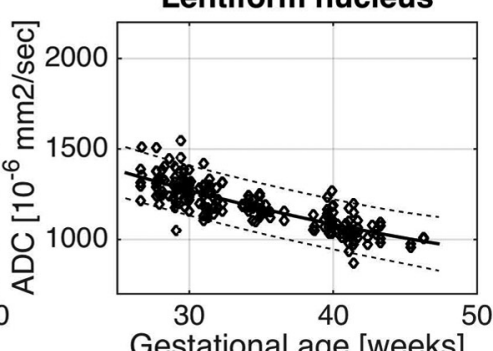

FIG 1. Continued. ADC values.

though subtle differences between fetuses at 37 weeks of gestation and preterm infants at TEA were reported. ${ }^{23}$ No fetal data of T1 values are available.

While a multitude of data exist for preterm infants at TEA, ${ }^{24,25}$ only a few studies have described the longitudinal evolution of quantitative brain MR imaging markers. In the late 1990s, Hüppi et $\mathrm{al}^{9}$ reported changes of ADC and FA in the WM of preterm infants between early life and TEA. Their group showed differences in WM fiber organization and delay of development at TEA compared with term. Miller et al, ${ }^{7}$ by using DTI, also showed serial differences in maturation in 23 infants with and without WM injury. Later, Nossin-Manor et $\mathrm{al}^{11}$ assessed tissue organization longitudinally and were able to show a difference in maturation according to the different ROIs and the different techniques used, such as magnetization transfer, DTI, and T1 imaging. Recently Kersbergen et $\mathrm{al}^{8}$ provided reference diffusivity values from scans obtained between 30 weeks and TEA. Compared with these studies, our ADC and FA values were similar to those in Nossin-
Manor ${ }^{11}$ and Partridge et al, ${ }^{26}$ and FA values were slightly higher than those reported by other groups. ${ }^{8,24}$ The relatively large heterogeneity of FA values in the literature is difficult to explain with certainty. However, it may involve several potential confounders: 1) b-value ranges from 600 to $1000 \mathrm{~s} / \mathrm{mm}^{2}, 27$ 2) slightly different tensor reconstruction strategies, 3) drawing and selection of the ROIs (this may actually be the main causative agent), and 4) some unsuspected systematic differences between the cohorts.

Concerning $\mathrm{T} 1$ relaxometry, only a few studies relate $\mathrm{T} 1$ values in infancy, ${ }^{13}$ neonates ${ }^{15}$ and premature infants, ${ }^{11,14}$ albeit it provides reliable quantitative measures and high contrast images. We were able not only to measure $\mathrm{T} 1$ relaxometry serially in premature brains but also to show a strong correlation between $\mathrm{ADC}$ and $\mathrm{T} 1$ values, enhancing its validity toward clinical use. Moreover, we described a closer distribution of T1 values compared with ADC, in particular at TEA. Compared with existing data, ${ }^{11,14}$ our findings were similar.

When performing serial imaging of preterm brain by using specific MR imaging markers, it is important to understand the different 

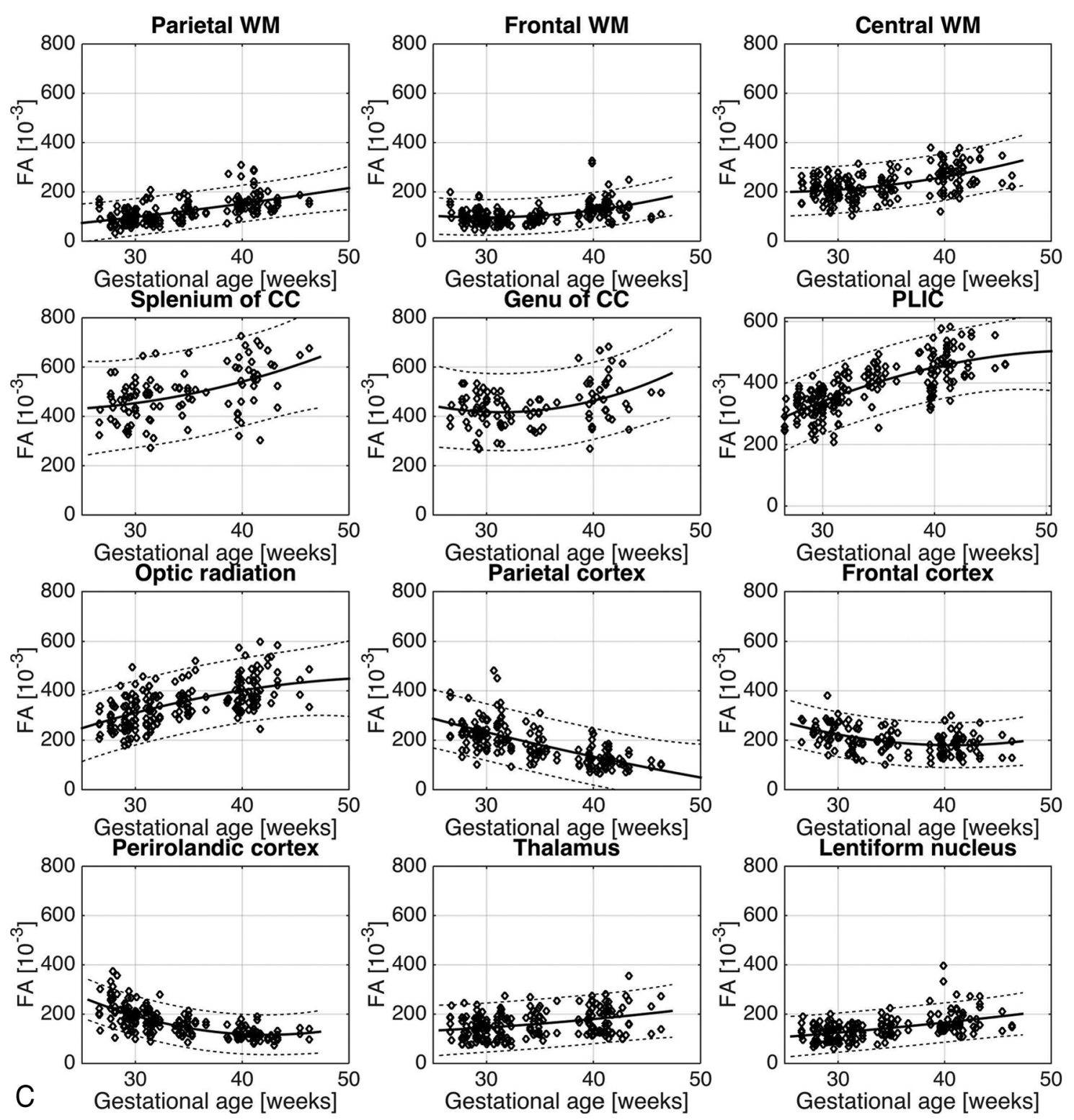

FIG 1. Continued. FA values.

processes involved in brain maturation during the last trimester of gestation, such as neuronal differentiation, premyelination with water-content reduction, increase of lipid concentration, maturation of preoligodendrocytes, and finally the beginning of axonal myelination and development of connecting fibers. ${ }^{5,28}$

Diffusion and T1 relaxation time are sensitive to changes in tissue water content and compartmentalization. Mean diffusivity reflects intra- and extracellular water mobility and provides information about cellular and axonal density and myelination. Moreover, T1 relaxation time also provides information about lipid concentration associated with myelin production, cholesterol, and macromolecules (galactocerebrosides) $)^{11,13}$ and can, therefore, be considered as an optimal marker of brain maturation. FA represents a measure of tissue directionality sensitive to the degree of axonal alignment, fiber diameter, and consecutive early processes of premyelination. ${ }^{9}$

To draw brain maturational trajectories in very preterm infants, we used the above-mentioned 3 imaging biomarkers. In the WM fiber tracts (PLIC, optic radiation, and corona radiata), the linear decline of $\mathrm{ADC}$ and $\mathrm{T} 1$ reflects reduction in water content, fiber packaging, and early processes of myelination, especially for the PLIC from 36 weeks onward. In these structures, the steep slope of FA represents the progressive development of unidirectional (PLIC) or multidirectional (corona radiata) fibers. The splenium and genu of the corpus callosum consist of tightly packed fibers with a high degree of coherent parallel organization, which myelinate only at 3 and 5 months after term, respectively. ${ }^{11,29}$ This feature accounts for little change with time for ADC and T1 values and high absolute FA values. In the frontal and parietal WM, we observed a shouldered curve on ADC and T1 maps that could be explained by the inclusion of the subplate zone that peaks between 29 to 32 gestational weeks and then gradually disappears. The subplate has a high water content, ${ }^{5,30,31}$ is particularly voluminous in the frontal $\mathrm{WM},{ }^{21,32}$ and accounts for elevated $\mathrm{ADC}$ and $\mathrm{T} 1$ values.

In the basal ganglia and thalamus, the $\mathrm{ADC}$ and $\mathrm{T} 1$ values showed a gradual decrease due to fast neuronal densification with 
ongoing myelination, as described starting around 26 weeks. ${ }^{29}$ In FA, these subcortical GM structures exhibited little change with time because of the low directionality of neuronal and glial content. In the frontal and parietal cortex, the evolution of ADC and $\mathrm{T} 1$ values showed a shouldered curve with maximum values around 35 weeks, possibly related to programmed cell death and additional neuropil before 35 weeks $^{33,34}$ and higher neuronal attenuation afterward. The perirolandic cortex seemed to mature faster than other cortical regions, and this accelerated maturation has been described in areas with primary function, such as the sensorimotor cortex. ${ }^{34,35}$ The observed decline of the FA is attributed to the preferential reduction in the radial component of water diffusivity, reflecting the loss of the radial glial cells and the extension of dendrites of pyramidal cells. ${ }^{32-35}$

The present study has a number of limitations. We assumed that our cohort was at cerebral low-risk, given their clinical evolution and the absence of major cerebral lesions. Neurodevelopmental outcome at 6 and 18 months showed that no patient had cerebral palsy, blindness, or hearing loss, and the distribution of developmental scores was typical for this population of preterm infants. Furthermore, because patients with moderate or severe brain lesions were scarce, we could not compare their values with those obtained from the selected low-risk patients. Finally, comparison with healthy control fetuses and term neonates was not available.

In this study, we propose reference values of T1 relaxometry, which could represent a precise and complementary tool to investigate brain development with time. We speculate that deviation of the described trajectories might reflect disturbed maturation, and this could add valuable information for the diagnosis of encephalopathy of prematurity. ${ }^{4,5}$ Kinney and Volpe ${ }^{28}$ described "altered developmental trajectories, combined with acquired insults and reparative phenomena" to characterize this entity, in which all the structures detailed above are affected. Oligodendrocyte differentiation, axonal growth, subplate organization, and maturation of the subcortical structures represent features that are likely to be affected by prematurity.

\section{CONCLUSIONS}

Our study evaluated, longitudinally and serially, the cerebral developmental trajectories of a cohort of cerebral low-risk preterm infants born at fewer than 30 weeks of gestation. On the successive MP2RAGE and DTI sequences, we observed a gradual decline with time of ADC and T1 relaxation time and changes of FA in the described 12 ROIs, reflecting the specific and sequential maturational changes occurring during development in the WM and GM microstructures. T1 maps confer high contrast, are easy to analyze, and thus appear as a promising complementary biomarker of cerebral maturation. We provide reference values for $\mathrm{T} 1$ relaxation, $\mathrm{ADC}$, and FA, and we speculate that deviation thereof might reflect disturbed cerebral maturation; the correlation of this disturbed maturation with neurodevelopmental outcome remains to be addressed.

\section{ACKNOWLEDGMENTS}

We thank Professor J.-F. Tolsa for his tremendous support.
Disclosures: Juliane Schneider-RELATED: Swiss National Science Foundation, Comments: National Grant (No. 33CM30-124101) allocated to a multidisciplinary project on brain development in preterm infants, performed in 3 academic sites, of which the University Hospital of Lausanne is 1 partner; Support for Travel to Meetings for the Study or Other Purposes: Swiss National Science Foundation (National Grant (No. 33CM30-124101). Tobias Kober-UNRELATED: Employment: I have been an employee of Siemens Healthcare Switzerland since 2011. Petra S. Hüppi-RELATED: Grant: Swiss National Science Foundation*; UNRELATED: Grants/Grants Pending: Swiss National Science Foundation, ${ }^{*}$ European Commission, ${ }^{*}$ Nestlé Research Center.* Patric Hagmann—RELATED: Grant: Leenaards Foundation*; UNRELATED: Grants/Grants Pending: Swiss National Science Foundation.* Anita TruttmannRELATED: Grant: Swiss National Science Foundation.* *Money paid to the institution.

\section{REFERENCES}

1. Van't Hooft J, van der Lee JH, Opmeer BC, et al. Predicting developmental outcomes in premature infants by term equivalent MRI: systematic review and meta-analysis. Syst Rev 2015;4:71 CrossRef Medline

2. Moore T, Hennessy EM, Myles J, et al. Neurological and developmental outcome in extremely preterm children born in England in 1995 and 2006: the EPICure studies. BMJ 2012;345:e7961 CrossRef Medline

3. Marret S, Marchand-Martin L, Picaud JC, et al; EPIPAGE Study Group. Brain injury in very preterm children and neurosensory and cognitive disabilities during childhood: the EPIPAGE cohort study. PLoS One 2013;8:e62683 CrossRef Medline

4. Back SA, Miller SP. Brain injury in premature neonates: a primary cerebral dysmaturation disorder? Ann Neurol 2014;75:469-86 CrossRef Medline

5. Volpe JJ. Brain injury in premature infants: a complex amalgam of destructive and developmental disturbances. Lancet Neurol 2009;8: 110-24 CrossRef Medline

6. Volpe JJ. Neuronal proliferation, migration, organization, and myelination. In: Neurology of the Newborn. 5th ed. New York: Saunders; 2008:51-117

7. Miller SP, Vigneron DB, Henry RG, et al. Serial quantitative diffusion tensor MRI of the premature brain: development in newborns with and without injury. J Magn Reson Imaging 2002;16:621-32 CrossRef Medline

8. Kersbergen KJ, Leemans A, Groenendaal F, et al. Microstructural brain development between 30 and 40 weeks corrected age in a longitudinal cohort of extremely preterm infants. Neuroimage 2014; 103:214-24 CrossRef Medline

9. Hüppi PS, Maier SE, Peled S, et al. Microstructural development of human newborn cerebral white matter assessed in vivo by diffusion tensor magnetic resonance imaging. Pediatr Res 1998;44:584-90 CrossRef Medline

10. Chau V, Synnes A, Grunau RE, et al. Abnormal brain maturation in preterm neonates associated with adverse developmental outcomes. Neurology 2013;81:2082-89 CrossRef Medline

11. Nossin-Manor R, Card D, Morris D, et al. Quantitative MRI in the very preterm brain: assessing tissue organization and myelination using magnetization transfer, diffusion tensor and $T_{1}$ imaging. Neuroimage 2013;64:505-16 CrossRef Medline

12. Marques JP, Kober T, Krueger G, et al. MP2RAGE, a self bias-field corrected sequence for improved segmentation and T1-mapping at high field. Neuroimage 2010;49:1271-81 CrossRef Medline

13. Deoni SC, Dean DC 3rd, O'Muircheartaigh J, et al. Investigating white matter development in infancy and early childhood using myelin water faction and relaxation time mapping. Neuroimage 2012;63:1038-53 CrossRef Medline

14. Williams LA, Gelman N, Picot PA, et al. Neonatal brain: regional variability of in vivo MR imaging relaxation rates at $3.0 \mathrm{~T}$-initial experience. Radiology 2005;235:595-603 CrossRef Medline

15. Maitre NL, Slaughter JC, Stark AR, et al. Validation of a brain MRI relaxometry protocol to measure effects of preterm birth at a flexible postnatal age. BMC Pediatr 2014;14:84 CrossRef Medline

16. Dubowitz LM, Dubowitz V, Palmer P, et al. A new approach to the 
neurological assessment of the preterm and full-term newborn infant. Brain Dev 1980;2:3-14 CrossRef Medline

17. Basser PJ, Mattiello J, LeBihan D. MR diffusion tensor spectroscopy and imaging. Biophys J 1994;66:259-67 CrossRef Medline

18. Kidokoro H, Neil JJ, Inder TE. New MR imaging assessment tool to define brain abnormalities in very preterm infants at term. AJNR Am J Neuroradiol 2013;34:2208-14 CrossRef Medline

19. Papile LA, Burstein J, Burstein R, et al. Incidence and evolution of subependymal and intraventricular hemorrhage: a study of infants with birth weights less than 1,500 gm. J Pediatr 1978;92:529-34 CrossRef Medline

20. Schneider MM, Berman JI, Baumer FM, et al. Normative apparent diffusion coefficient values in the developing fetal brain. AJNR Am J Neuroradiol 2009;30:1799-803 CrossRef Medline

21. Schneider JF, Confort-Gouny S, Le Fur Y, et al. Diffusion-weighted imaging in normal fetal brain maturation. Eur Radiol 2007;17: 2422-29 CrossRef Medline

22. Trivedi R, Gupta RK, Husain N, et al. Region-specific maturation of cerebral cortex in human fetal brain: diffusion tensor imaging and histology. Neuroradiology 2009;51:567-76 CrossRef Medline

23. Viola A, Confort-Gouny S, Schneider JF, et al. Is brain maturation comparable in fetuses and premature neonates at term equivalent age? AJNR Am J Neuroradiol 2011;32:1451-58 CrossRef Medline

24. Rose J, Vassar R, Cahill-Rowley K, et al. Brain microstructural development at near-term age in very-low-birth-weight preterm infants: an atlas-based diffusion imaging study. Neuroimage 2014;86: 244-56 CrossRef Medline

25. Oishi K, Mori S, Donohue PK, et al. Multi-contrast human neonatal brain atlas: application to normal neonate development analysis. Neuroimage 2011;56:8-20 CrossRef Medline

26. Partridge SC, Mukherjee P, Henry RG, et al. Diffusion tensor imaging: serial quantitation of white matter tract maturity in premature newborns. Neuroimage 2004;22:1302-14 CrossRef Medline

27. Chung AW, Thomas DL, Ordidge RJ, et al. Diffusion tensor parameters and principal eigenvector coherence: relation to $b$-value intervals and field strength. Magn Reson Imaging 2013;31:742-47 CrossRef Medline

28. Kinney HC, Volpe JJ. Modeling the encephalopathy of prematurity in animals: the important role of translational research. Neurol Res Int 2012;2012:295389 CrossRef Medline

29. Counsell SJ, Maalouf EF, Fletcher AM, et al. MR imaging assessment of myelination in the very preterm brain. AJNR Am J Neuroradiol 2002;23:872-81 Medline

30. Kostović I, Jovanov-Milošević N, Radoš M, et al. Perinatal and early postnatal reorganization of the subplate and related cellular compartments in the human cerebral wall as revealed by histological and MRI approaches. Brain Struct Funct 2014;219:231-53 CrossRef Medline

31. Raybaud C, Ahmad T, Rastegar N, et al. The premature brain: developmental and lesional anatomy. Neuroradiology 2013;55(suppl 2): 23-40 CrossRef Medline

32. Dudink J, Buijs J, Govaert P, et al. Diffusion tensor imaging of the cortical plate and subplate in very-low-birth-weight infants. Pediatr Radiol 2010;40:1397-404 CrossRef Medline

33. McKinstry RC, Mathur A, Miller JH, et al. Radial organization of developing preterm human cerebral cortex revealed by non-invasive water diffusion anisotropy MRI. Cereb Cortex 2002;12:1237-43 CrossRef Medline

34. Ball G, Srinivasan L, Aljabar P, et al. Development of cortical microstructure in the preterm human brain. Proc Natl Acad Sci U S A 2013;110:9541-46 CrossRef Medline

35. Deipolyi AR, Mukherjee P, Gill K, et al. Comparing microstructural and macrostructural development of the cerebral cortex in premature newborns: diffusion tensor imaging versus cortical gyration. Neuroimage 2005;27:579-86 CrossRef Medline

36. Rose J, Butler EE, Lamont LE, et al. Neonatal brain structure on MRI and diffusion tensor imaging, sex, and neurodevelopment in verylow-birthweight preterm children. Dev Med Child Neurol 2009;51: 526-35 CrossRef Medline

37. Cheong JL, Thompson DK, Wand HX, et al. Abnormal white matter signal on MR Imaging is related to abnormal tissue microstructure. AJNR Am J Neuroradiol 2009;30:623-28 CrossRef Medline

38. Jones RA, Palasis S, Grattan-Smith JD. MRI of the neonatal brain: optimization of spin-echo parameters. AJR Am J Roentgenol 2004; 182:367-72 Medline 